\title{
Composition of Uroliths seen in patients in Abuja, Nigeria: a single centre retrospective analysis of 155 stones
}

\author{
Celsus Ukelina Undie ${ }^{*}$ (]) Ewomazino Ibanga Nnana and Kalenebari Raymond Torporo
}

\begin{abstract}
Background: Uroliths are stones formed in the urinary tract. Analysis of stones helps to identify risk factors for their development and prevention of recurrence. Standard stone analysis using modern technology is not routinely done in Nigeria. This study sought to determine the chemical composition of urinary stones seen in Abuja, Nigeria.

Methods: This was a retrospective study on composition of uroliths. Urinary stones surgically removed from 155 patients through minimal access surgical procedures between January 2015 and August 2019 were analysed. Optical crystallography and infrared spectroscopy were used to determine the chemical composition of the urinary stones.

Results: A total of 155 urinary stones were assembled from the patients. More stones were removed from male patients and the male to female ratio was 1.9:1. Stones were rare in the extremes of age. The predominant location (89.7\%) of stones was in the upper urinary tract. All stones were of mixed composition with calcium oxalate accounting for $93.55 \%$. Calcium oxalate, calcium phosphate and uric acid stones were more common in the upper tract, while 2 of the 3 struvite stones were found in the lower tract.
\end{abstract}

Conclusion: Stones found in this study were of mixed composition with the most common constituent being Calcium oxalate and the least common, struvite.

Keywords: Uroliths, Analysis, Composition

\section{Background}

Urolithiasis is a common cause of presentation and referral to Urology clinics. Uroliths are stones found within the urinary tract [1]. They are products of chemical substances in the urine which are present in larger than normal quantities with the excess precipitating to form stones [2]. These substances include but are not limited to calcium oxalate existing either in the monohydrate form (whewellite) or in the dihydrate form (whedellite), calcium phosphate, uric acid, cystine and Magnesium Ammonium Phosphate (struvite).

*Correspondence: cuundie@yahoo.com; urologist@kelinahospital.com Kelina Hospital, 3rd Avenue, Gwarinpa, PMB 48, Abuja 900001, FCT, Nigeria
Urolithiasis is worldwide in distribution [3] though more common in developed regions of the world [4]. The incidence appears to be on the increase worldwide $[4,5]$. In the United States of America, the prevalence of kidney stones for the adult population reportedly increased by $8.8 \%$ from 2007 to 2010 [6]. The prevalence of the condition is higher among men than women both in Nigeria ( 1 , 2 ) and other parts of the world [7, 8]. It is more common between the 3rd and 6th decades of life [9]. It is estimated that without metaphylaxis, within $5-10$ years, $50 \%$ of stone formers will have a recurrence and within 20 years, up to $75 \%$ will have a recurrence [10].

Knowledge of the composition of urinary stones can help to identify risk factors for their formation, guide treatment and prevent recurrence. Both the European Association of Urology (EAU) [11] and the American 
Urological Association (AUA) [12] recommend that stones from all first time stone formers should be analysed [11]. Different methods for the analysis of kidney stones exist, each with its peculiar advantages and limitations. Amongst them are wet chemical analysis, which has almost been completely abandoned except in resource-poor settings because of its high error rate [13], its ability to recognize only single ions and radicals [14] as well as its inability to differentiate between the types of calcium oxalate stones [15]. Other techniques for analysis include X-ray diffraction and Infrared spectroscopy $[15,16]$. The EUA guidelines recommend the use of infrared spectroscopy and x-ray diffraction for analysis while accepting that polarization microscopy can give equally reliable results [11]. The guidelines do not advocate the use of chemical analysis (wet chemistry) as it is generally deemed to be obsolete [11].

In spite of the recommendations by recognized Urological authorities [11, 12], analysis of kidney stones in Nigeria is not routinely done. One Nigerian study showed that of 88 Doctors who had managed renal stones, $51.1 \%$ did not send the stones for analysis and $40 \%$ of these felt it was unnecessary [17]. Even when analysis is attempted, wet chemical analysis alone, known for its numerous limitations, is used.

The technology for standard analysis is expensive and is not readily available in Africa. In our literature search, there was no report of analysis in Nigeria using techniques recommended by the EAU and AUA. Therefore, to meet the recommendations of the EAU and AUA, uroliths have to be sent outside Africa for analysis. This is not only time-consuming but equally expensive. It is thus understandable that most management protocols in Nigeria do not incorporate stone analysis. Even when laboratories for analysis are found, the average patient may consider it too expensive for out of pocket spending.

The aims of this study, then, are to identify the major components of uroliths retrieved during endoscopic surgeries from patients managed for urolithiasis in Abuja, Nigeria, using EAU and AUA recommended analytical methods and to determine if stone composition in our West African sub-region, and in particular Nigeria, is similar to what is found in other parts of the world.

\section{Methods}

\subsection{Design}

This was a retrospective, cross-sectional study on uroliths collected from patients during percutaneous nephrolithotomy (PCNL and Mini-PCNL), retrograde intrarenal surgery (RIRS), uretero-renoscopy (URS) and Urethrocystoscopy for urolithiasis in Abuja, Nigeria.

\subsection{Setting}

The hospital is a highly specialized urological facility that offers minimal access surgical procedures including PCNL and Mini-PCNL, URS, RIRS, combined with laser, ultrasonic or pneumatic lithotripsy either independently or sometimes in combination (the Swiss lithoclast master) for the removal of urinary tract stones.

The samples were dried and sent to Urolab with head office in India, for analysis. The analysis was done using combination of Infra-Red Spectroscopy and Optical Crystallography as recommended by the EUA and AUA.

Stones were assayed for the presence of whewellite, wheddellite, brushite, carbonate, dahllite, uric acid, ammonium urate, struvite and cystine and were classified as Calcium oxalate stones if they contained whewellite and/or wheddellite, Calcium phosphate if they contained brushite, carbonate or dahllite, uric acid stones if they contained uric acid or ammonium urate and struvite stones if they contained magnesium ammonium phosphate.

\section{Results}

Of 155 stones sent for analysis, stones from 2 patients contained artefacts only. These patients were excluded from the study.

The findings of this study show that of the 153 patients whose stones were analysed, 100(65.4\%) were male and $53(34.6 \%)$ were female with a male to female ratio of 1.9:1. Stones were commonest (27.5\%) in patients between 31 and 40 years age bracket followed by those in the $41-50$ age group (Table 1 ).

Table 2 shows that stones in $125(81.7 \%)$ patients were found at a single site, the kidney being the most common location in 103(67.3\%) patients.

Table 1 Demographic characteristics of study patients

\begin{tabular}{lll}
\hline Variable & Number $(\boldsymbol{n}=\mathbf{1 5 3})$ & Percentage \\
\hline Age (years) & 2 & 1.3 \\
$0-10$ & 3 & 2.0 \\
$11-20$ & 11 & 7.1 \\
$21-30$ & 42 & 27.5 \\
$31-40$ & 40 & 26.1 \\
$41-50$ & 29 & 19.0 \\
$51-60$ & 20 & 13.1 \\
$61-70$ & 6 & 3.9 \\
$\geq 71$ & & \\
Sex & 100 & 65.4 \\
Male & 53 & 34.6 \\
Female &
\end{tabular}


Table 2 Location of renal stones in affected patients

\begin{tabular}{lll}
\hline Location of stones & Frequency $(\boldsymbol{n = 1 5 3 )}$ & Percentage \\
\hline Single & 125 & 81.7 \\
Multiple & 28 & 18.3 \\
Stone site & & \\
Kidney (Unilateral) & 80 & 52.3 \\
Ureter & 33 & 21.6 \\
Bladder & 14 & 9.2 \\
Urethra & 2 & 1.3 \\
Kidney (Bilateral) & 13 & 8.5 \\
Kidney + Ureter & 8 & 5.2 \\
Kidney + Bladder & 2 & 1.3 \\
Ureter + Bladder & 1 & 0.7 \\
UPPER TRACT $(n=136)$ (side affected) & \\
Right & 65 & 42.5 \\
Left & 49 & 32.0 \\
Bilateral & 22 & 14.4 \\
\hline
\end{tabular}

Stones were more commonly seen $(27.5 \%)$ in the $31-40$ age group. More males $(29.0 \%)$ in the $41-50$ age bracket were affected (Fig. 1).

Calcium oxalate, alone or in combination, was the commonest stone constituent found in both sexes (Table 3).

While calcium oxalate stones were more common in the fourth decade of life, the struvite stones were found only in the elderly (Fig. 2).

\section{Discussion}

The present study shows that more males were seen with urolithiasis than females. This finding is in agreement with other studies done in Enugu, Nigeria; Kelantan, Malaysia and South India where a male to female ratio of 3.3:1 [1] 1.35:1 [18] and 1.8:1 [8] was found. The higher prevalence in males may be due to their higher level of androgens which have been reported to promote stone formation, while estrogens in females suppress stone formation [19]. In Kano, Northern Nigeria, however, much higher male to female ratio of 6:1 [2] was seen. The authors attributed this higher prevalence to more strenuous activities men were involved in. This part of the country has a hot, arid and dry climate and is close to the Sahara desert, which predisposes men to more dehydration and stone formation or recurrence. Genetic factors are thought to outweigh the effect of climate on stone formation [20], however, and this could explain the higher incidence of urolithiasis in the Caucasian populations than in blacks.

Majority of patients with stones in this study were middle-aged. This is consistent with reports from other studies which show that urinary stone disease peaks in the 4th and 5th decades of life [21]. This may be particularly so in our environment, where at this age, people are more likely to work outdoors for long periods of time in the tropical heat and are thus prone to dehydration. Obesity, a known risk factor for stone formation [22, 23] is also higher in this age group [24].

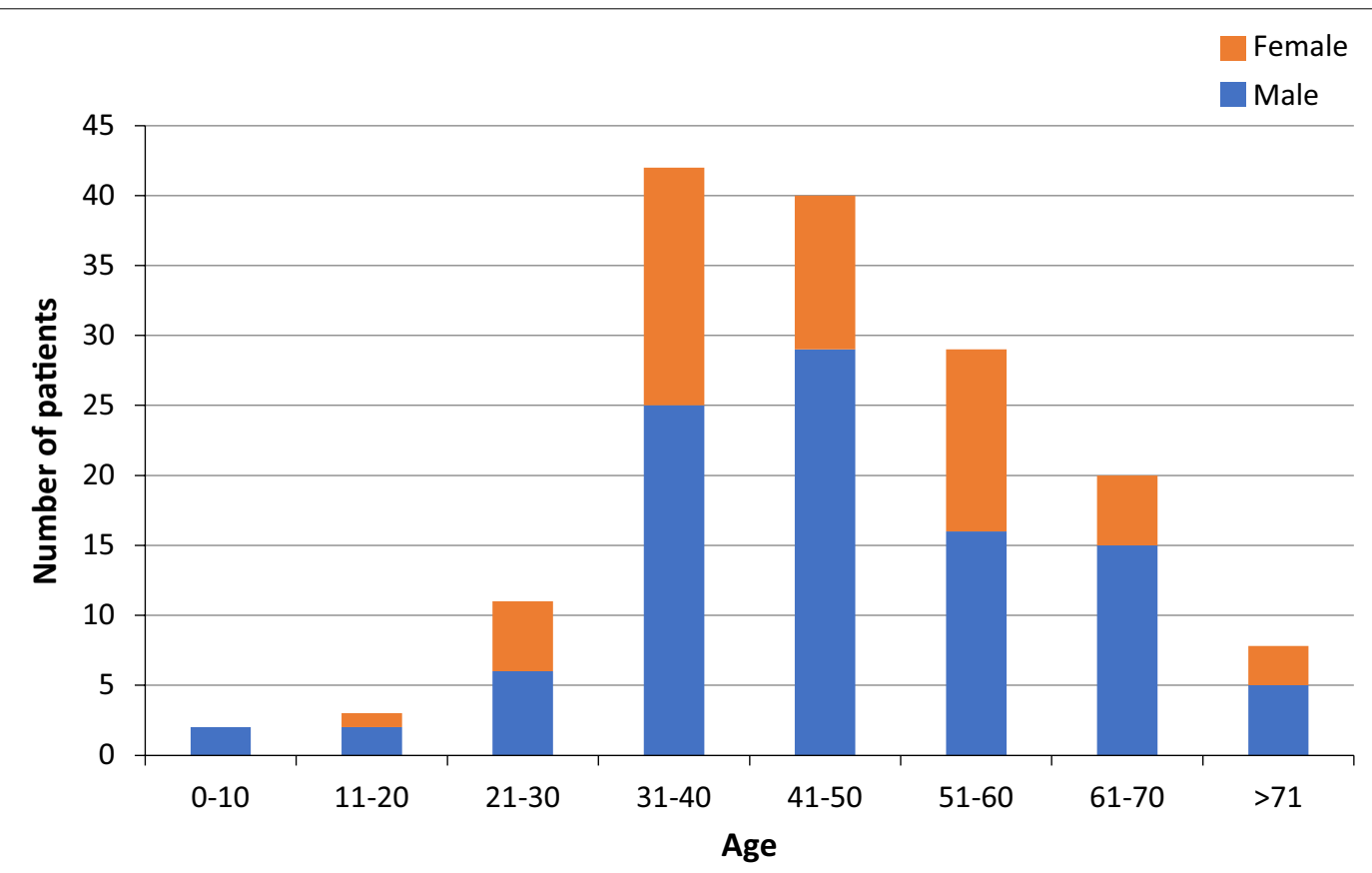

Fig. 1 Distribution of the stones by age and sex of patients 
Table 3 Composition of the renal stones by sex

\begin{tabular}{llll}
\hline Stone composition & Male & Female & Total \\
\hline $\mathrm{CaO}$ & $52(52.0 \%)$ & $25(47.2 \%)$ & $77(50.3 \%)$ \\
$\mathrm{CaO}+\mathrm{CaP}$ & $21(21.0 \%)$ & $19(35.8 \%)$ & $40(26.1 \%)$ \\
$\mathrm{CaO}+$ Uric acid & $22(22.0 \%)$ & $5(9.4 \%)$ & $27(17.6 \%)$ \\
Uric acid & $1(1.0 \%)$ & $2(3.8 \%)$ & $3(2.0 \%)$ \\
$\mathrm{CaP}+$ Struvite & $1(1.0 \%)$ & $1(1.9 \%)$ & $2(1.3 \%)$ \\
$\mathrm{CaP}+$ Uric acid & $1(1.0 \%)$ & $1(1.9 \%)$ & $2(1.3 \%)$ \\
$\mathrm{CaO}+$ CaP + Uric acid & $1(1.0 \%)$ & $0(0 \%)$ & $1(0.7 \%)$ \\
Uric acid + struvite & $1(1.0 \%)$ & $0(0 \%)$ & $1(0.7 \%)$ \\
Total & $100(100 \%)$ & $53(100 \%)$ & $153(100 \%)$ \\
\hline
\end{tabular}

There were only two patients below the age of 10 and one above 90. Kidney stones are generally said to be rare in the extremes of life [25]. However, children can also develop urinary stones, as seen in our study, and a conscious effort should be made to exclude the presence of kidney stone disease in children presenting with symptoms, such as flank pain or haematuria.

As in this study, authors from Kenya, India and China reported that the majority of stones seen were in the upper tract [16, 26, 27]. There were 2 earlier reports from Nigeria showing the majority of stones, 55.7\% [2] and $75.6 \%$ [28], in the lower urinary tract. In those centres, mostly open surgical procedures are done, and several small stones in the upper tract could have been missed if such patients presented for surgery. If a Urologist is unable to palpate the stone in the kidney during open surgery, for example, he is not likely to be able to remove it. The urinary bladder was the commonest site for stones removed at surgery in both Northern and Eastern Nigeria $[2,28]$, where open surgery was the main modality of treatment. Also some of these stones may have been found incidentally during other surgeries in the lower urinary tract, such as for urethral strictures and enlarged prostate. In contrast, in this study, where only endoscopic procedures were done, $67.3 \%$ (103) of the stones were located in the kidney, a finding consistent with reports from centres where endoscopic treatment for stones is available.

Calcium oxalate existing either in monohydrate or dihydrate form or mixed with other stone constituents, was the most common urolith seen. This was similar to what was found in the United States of America [29] and South Eastern Europe [30]. In some parts of Africa and the middle East, however, while calcium oxalate stones were the most common as in this study, uric acid stones were the second most common stone type [31,32].

Across all ages, Calcium oxalate stones were the most common stones seen in our patients with a peak between ages 41-50 years. Calcium oxalate stones were also the most common stones found in both males and females similar to findings in Asia [33]. Unlike our own findings in this study, calcium oxalate stones were found to peak between 31 and 40 years.

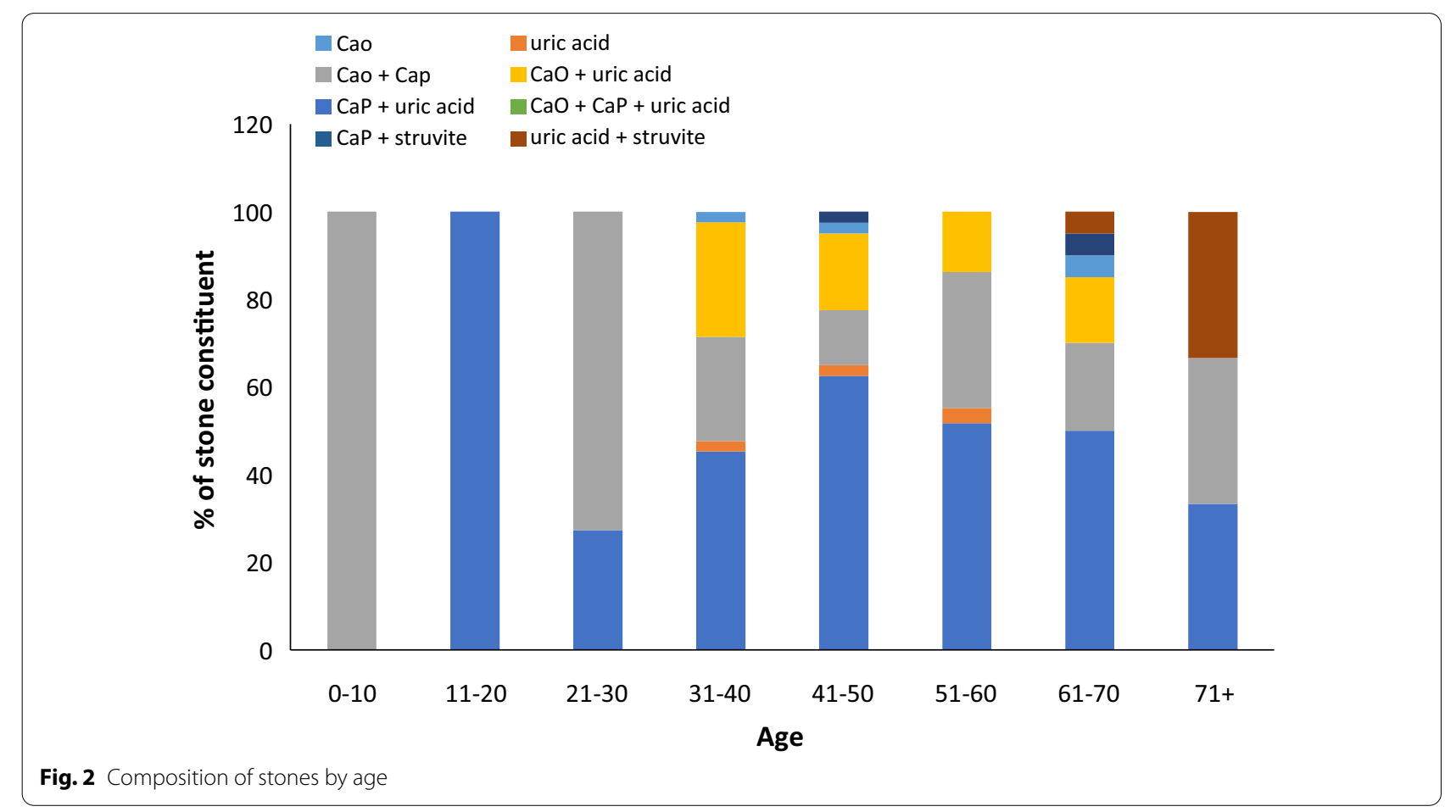


Struvite stones are thought to be more common in women [34] and persons over 50 years presumably because they are more prone to urinary tract infections. Two of the three patients with struvite stones in our series were males over 50 years. The 3 rd patient was a female. Elderly male patients with bladder outlet obstruction are more predisposed to urinary stasis and infection. This may explain the greater proportion of struvite stones in these patients. Calcium oxalate stones were more common in the upper urinary tract, while 2 of the 3 struvite stones were found in the bladder. In our study, 2 samples were reported as artefacts. Interestingly, we did not find cystine, matrix, drug-induced or any other rare stone. This may be due to our sample size. Cystine stones are said to be rare, generally, occurring in people with cystinuria, a genetic condition that is reported only occasionally in blacks [35]. Cystinuria is reported to occur in only 1: 600 to $1: 17,000$ individuals, even for populations that were studied [36]. Matrix stones are also very rare, and often present a diagnostic dilemma [37].

\section{Conclusion}

Stones in our experience were of mixed composition. The most common constituent of stones amongst Nigerians across all ages was calcium oxalate. The least common stone constituent represented was struvite. All stones, including calcium oxalate stones were more common in males than in females. Calcium oxalate stones were more common in the upper tract than in the lower tract, while 2 of the 3 struvite stones were found in the bladder.

\section{Abbreviations}

AUA: American Urological Association; EUA: European Association of Urology; PCNL: Percutaneous nephrolithotomy; Mini-PCNL: Mini percutaneous nephrolithotomy; URS: Uretero-renoscopy; RIRS: Retrograde intrarenal surgery; $\mathrm{CaO}$ : Calcium oxalate; CaP: Calcium phosphate.

\section{Acknowledgements}

We acknowledge the role of Prof. Friday Odey who provided editorial assistance prior to submission.

\section{Authors' contributions}

CUU conceptualized and designed the research. EIN recruited participants and collected data. EIN interpreted results on urolith's localization and constituents. KRT contributed to interpretation of the results, prepared figures and tables and extensively reviewed all references. All authors discussed the results and were major contributors in writing the manuscript. All authors read and approved the final manuscript.

\section{Funding}

Kelina Hospital, Abuja was the source of funding for the research, from participant's recruitment, data collection and analysis to writing the manuscript.

\section{Availability of data and materials}

The datasets used and/or analysed during the current study are available from the corresponding author on reasonable request.

\section{Declarations}

Ethics approval and consent to participate

Ethical approval for the study was given by the Federal CapitalTerritory Health Research Ethics Committee with Approval Number:FHREC/2O2O|O1/112/0311-20. Consent to Participate is notapplicable as it is a retrospective study

\section{Consent for publication}

Notapplicable.

\section{Competing interests}

The authors declare that they have no competing interests.

Received: 21 December 2020 Accepted: 17 June 2021

Published online: 02 July 2021

\section{References}

1. Meka IA, Ugonabo MC, Ebede SO, Agbo EO (2018) Composition of uroliths in a tertiary hospital in South East Nigeria. Afr Health Sci 18(2):437445. https://doi.org/10.4314/ahs.v18i2.29

2. Emokpae MA, Gadzama AA (2012) Anatomical distribution and biochemical composition of urolithiasis in Kano, northern Nigeria. Int J Biol Chem Sci 6(3):1158-1166. https://doi.org/10.4314/ijbcs.v6i3

3. Atul S, Papiya B (2017) A review on epidemiology and etiology of renal stone. Am J Drug Discov Dev 7:54-62. https://doi.org/10.3923/ajdd.2017. 54.62

4. Kirkali Z, Rasooly R, Star RA, Rodgers GP (2015) Urinary stone disease: progress, status, and needs. Urology 86(4):651-653. https://doi.org/10. 1016/j.urology.2015.07.006

5. Romero V, Akpinar H, Assimos DG (2010) Kidney stones: a global picture of prevalence, incidence, and associated risk factors. Rev Urol 12(2-3):e86-e96

6. Scales CD, Smith AC, Hanley JM, Saigal CS, Urologic Diseases In America Project (2012) Prevalence of Kidney Stones in the United States. Eur Urol 62(1):160-165. https://doi.org/10.1016/j.eururo.2012.03.052

7. Nouri Al, Hassali MA (2018) Assessment of kidney stone disease prevalence in a teaching hospital. Afr J Urol 24(3):180-185. https://doi.org/10. 1016/j.afju.2018.05.003

8. Rachamalla RR, Konduru R (2018) A prospective study of cases of urolithiasis with reference to risk factors, surgery and outcomes. Int Surg J 5(12):3826-3830. https://doi.org/10.18203/2349-2902.isj20184687

9. Fakheri RJ, Goldfarb DS (2011) Ambient temperature as a contributor to kidney stone formation: implications of global warming. Kidney Int 79(11):1178-1185. https://doi.org/10.1038/ki.2011.76

10. Moe OW (2006) Kidney stones: pathophysiology and medical management. Lancet 367(9507):333-344. https://doi.org/10.1016/s0140-6736(06) 68071-9

11. Skolarikos A, Straub M, Knoll T, Sarica K, Seitz C, Petř́k A et al (2015) Metabolic evaluation and recurrence prevention for urinary stone patients: EAU guidelines. Eur Urol 67(4):750-763. https://doi.org/10.1016/j.eururo. 2014.10.029

12 Pearle MS, Goldfarb DS, Assimos DG, Curhan G, Denu-Ciocca CJ, Matlaga BR et al (2014) American Urological Association. Medical management of kidney stones: AUA guideline. J Urol 192(2):316-324. https://doi.org/10. 1016/j.juro.2014.05.006

13. Gilad R, Williams JC, Usman KD, Holland R, Golan S, Tor R et al (2017) Interpreting the results of chemical stone analysis in the era of modern stone analysis techniques. J Nephrol 30(1):135-140. https://doi.org/10. 1007/s40620-016-0274-9

14. Basiri A, Taheri M, Taheri F (2012) What is the state of the stone analysis techniques in urolithiasis? Urol J 9(2):445-454

15. Khan AH, Imran S, Talati J, Jafri L (2018) Fourier transform infrared spectroscopy for analysis of kidney stones. Investig Clin Urol 59(1):32-37. https://doi.org/10.4111/icu.2018.59.1.32

16. Wathigo FK, Hayombe A, Maina D (2017) Urolithiasis analysis in a multiethnic population at a tertiary hospital in Nairobi, Kenya. BMC Res Notes 10(1):158. https://doi.org/10.1186/s13104-017-2474-3 
17. Meka IA, Dilibe UC, Ugonabo MC, Ogbobe UU (2018) Chemical Analysis of uroliths: a two-center study of Doctors' practice and perspective in South-East Nigeria. Niger J Clin Pract 21:1265-1270. https://doi.org/10. 4103/njcp.njcp_250_18

18. Nouri Al, Hassali MA (2018) Assessment of kidney stone disease prevalence in a teaching hospital. African J Urol 24(3):180-185. https://doi.org/ 10.1016/j.afu.2018.05.003

19. Yagisawa T, Ito F, Osaka Y, Amano H, Kobayashi C, Toma H (2001) The influence of sex hormones on renal osteopontin expression and urinary constituents in experimental urolithiasis. J Urol 166:1078-1082

20. Sierakowski R, Finlayson B, Landes R (1979) Stone incidence as related to water hardness in different geographical regions of the United States. Urol Res 7(3):157-160. https://doi.org/10.1007/bf00257200

21. Tudor B, Man A, Mitranovici E, Tudor A (2013) Microbiological study of urinary calculi in patients with urinary infections. Acta Medica Transilvanica 2(2):245-249

22 Roudakova K, Monga M (2014) The evolving epidemiology of stone disease. Indian J Urol 30(1):44-48. https://doi.org/10.4103/0970-1591. 124206

23. Taylor EN, Stampfer MJ, Curhan GC (2005) Obesity, weight gain, and the risk of kidney stones. JAMA 293(4):455-462. https://doi.org/10.1001/jama. 293.4.455

24. Desalu OO, Salami AK, Oluboyo PO, Olarinoye JK (2008) Prevalence and socio-demographic determinants of obesity among adults in an urban Nigerian population. Sahel Med J 11(2):61-64. https://doi.org/10.4314/ smj2.v11i2.12970

25 Liu Y, Chen Y, Liao B, Luo D, Wang K, Li H, Zeng G (2018) Epidemiology of urolithiasis in Asia. Asian J Urol 5(4):205-214. https://doi.org/10.1016/j. ajur.2018.08.007

26 Jindal T, Mandal SN, Sonar P, Kamal MR, Ghosh N, Karmakar D (2014) Analysis of urinary stone composition in Eastern India by X-ray diffraction crystallography. Adv Biomed Res 3:203. https://doi.org/10.4103/22779175.142313

27. Luo J, Tuerxun A, Shataer A, Batuer A, Jiang C, Yizhou Z et al (2018) Kidney stone composition in third-world areas: what Kashgar tells us? J Endourol 32(6):465-470. https://doi.org/10.1089/end.2017.0860

28. Nnakenyi I, Nnakenyi E, Ugonabo M (2017) Pattern of urinary calculi at a Tertiary Hospital in Subsaharan Africa. IOSR J Dental Med Sci 16(2):66-70. https://doi.org/10.9790/0853-1610016670
29. Lieske JC, Rule AD, Krambeck AE, Williams JC, Bergstralh EJ, Mehta RA et al (2014) Stone composition as a function of age and sex. CJASN 9(12):2141-2146. https://doi.org/10.2215/CJN.05660614

30. Nemes-Nagy E, Maier A, Man A, Dénes L, Balogh-Sămărghițan V, Fazakas $Z$ et al (2015) Enhancing factors of urinary stones and evaluation of the incidence of various urinary stone types in hospitalized patients and outpatients. Ann R.S.C.B. 20(1):67-73

31. Bouatia M, Benramdane L, OuladBouyahyaldrissi M, Draoui M (2015) An epidemiological study on the composition of urinary stones in Morocco in relation to age and sex. African J Urol 21(3):194-197. https://doi.org/10. 1016/j.afju.2015.02.006

32. Malik NA, Hussain MA (2019) Analysis of chemical composition of urinary calculi from Northern border area of Saudi Arabia. J Pak Med Assoc 69(6):885-887

33. Wang S, Zhang Y, Zhang X, Tang Y, Li J (2020) Upper urinary tract stone compositions: the role of age and gender. Int braz j urol 46(1):70-80. https://doi.org/10.1590/s1677-5538.ibju.2019.0278

34. Flannigan RK, Battison A, De S, Humphreys MR, Bader M, Lellig E, Monga M, Chew BH, Lange D (2018) Evaluating factors that dictate struvite stone composition: a multi-institutional clinical experience from the EDGE Research Consortium. Can Urol Assoc J 12(4):131-136. https://doi.org/10. 5489/cuaj.4804

35. Al-Hermi B, Abbas B (2003) Cystinuria in Arab Contries. Saudi J Kidney Dis Tranpl 14(3):358-366

36. Cabello-Tomas M, Garcia-Gomez A, Guillen-Dominguez M (1999) Pilot screening programme for cystinuria in the Valencian Community. Eur $\mathrm{J}$ of Epidemiol 15:681-684. https://doi.org/10.1023/a:1007522215041

37 Lahyani M, Rhannam Y, Slaoui A, Touzani A, Karmouni T, Elkhader K, Koutani A, Andaloussi AIA (2016) Bilateral Kidney matrix stones: a rare case. Pan Afr Med J 25:102. https://doi.org/10.11604/pamj.2016.25.102.7926

\section{Publisher's Note}

Springer Nature remains neutral with regard to jurisdictional claims in published maps and institutional affiliations.

\section{Submit your manuscript to a SpringerOpen ${ }^{\circ}$ journal and benefit from:}

- Convenient online submission

- Rigorous peer review

- Open access: articles freely available online

- High visibility within the field

- Retaining the copyright to your article

Submit your next manuscript at $\boldsymbol{\nabla}$ springeropen.com 